\title{
Tecnologia Social, agroecologia e agricultura familiar: análises sobre um processo sociotécnico
}

\author{
Milena Pavan Serafim¹, Vanessa Maria Brito de Jesus², Janaína Faria ${ }^{2}$
}

Tecnologia Social (TS), agroecologia e agricultura familiar são temas que possuem diversas convergências. A agroecologia constitui um campo de estudos e práticas que procura deter as formas de degradação e exploração da natureza e da sociedade através de ações sociais coletivas de caráter participativo na busca da implantação de sistemas de agriculturas alternativas. Já a proposta da TS vai ao encontro de tais pressupostos, contribuindo com o debate ao inserir o papel da tecnologia para diminuição de desigualdades socioeconômicas. E a agricultura familiar é reconhecida como o segmento desejado para materializar essas propostas, portadoras de um futuro mais justo e igualitário. Nesse sentido, o presente artigo aborda uma experiência que envolve tais campos tendo como objeto de estudo a TS Produção Agroecológica Integrada e Sustentável (PAIS). Ele tem como objetivo analisar a dinâmica sociotécnica da PAIS, explorando especialmente alguns de seus limites percebidos a partir dos resultados obtidos pela pesquisa de campo. Parte desses limites se refere aos entraves de funcionamento da tecnologia analisada.

Palavras-chave: agricultura familiar, agroecologia, Tecnologia Social.

\section{Social Technology, agroecology e family-based agriculture: analyses on a sociotechnical process}

Social Technology, family farming and agroecology are subjects that have many convergences. Agroecology is a field of study and practice that seeks to stop the degradation and exploitation of nature and society through collective social action with a participatory approach in the quest for deployment of alternative agriculture. The proposal of Social Technology meets such assumptions, contributing to the debate by inserting the role of technology to reduce socioeconomic inequalities. And family farming is recognized as the desired segment to materialize these proposals, bearers of a more just and egalitarian future. Accordingly, this article discusses an experience involving such issues, namely the Social Technology Sustainable and Integrated Agroecological Production (PAIS in Portuguese). It aims to analyze the sociotechnical dynamics of PAIS, especially exploring some of its limits from the results obtained by field research. Part of the limits relates to the existing barriers for the operation of the analyzed technology. And the other part refers to a possible restriction to the wider proposal of Social Technology.

Key-words: family-based agriculture, agroecology, Social Technology.

\footnotetext{
1 Doutora em Política Científica e Tecnológica. Faculdade de Ciências Aplicadas (FCA), Universidade Estadual de Campinas (UNICAMP). Correspondência: Rua Pedro Zaccaria, 1300 - Jd. Santa Luiza. CEP 13484-350. Limeira, SP. E-mail: Milena.serafim@fca.unicamp.br.

${ }^{2}$ Mestre em Política Científica e Tecnológica. Departamento de Política Científica e Tecnológica (DPCT), Instituto de Geociências (IG), UNICAMP.
} 


\section{APRESENTAÇÃO}

Tecnologia Social (TS), agricultura familiar e agroecologia são temas que possuem diversas convergências. A agroecologia constitui um campo de estudos e práticas que procura deter as formas de degradação e exploração da natureza e da sociedade através de ações sociais coletivas de caráter participativo na busca da implantação de sistemas de agriculturas alternativas potencializadores da biodiversidade ecológica e da diversidade sociocultural [1]. Já a proposta da TS vai ao encontro de tais pressupostos, contribuindo com o debate ao inserir o papel da tecnologia para a diminuição de desigualdades socioeconômicas e a promoção da Segurança Alimentar e Nutricional (SAN). E a agricultura familiar é reconhecida como o segmento desejado para materializar essas propostas, portadoras de um futuro mais justo e igualitário, tendo em vista suas potenciais características de resistir à monocultura e à concentração de terra, de potencializar o acesso aos alimentos por parcela da população carente $^{3}$, de interagir com a cultura local e de resgatar seus hábitos alimentares, de promover a SAN do produtor e das famílias do seu entorno.

O segmento da agricultura familiar é responsável por mais da metade da produção de alimentos de subsistência do país. Conforme mostra o Censo Agropecuário de 2006, a agricultura familiar produz grande parte dos alimentos consumidos pela população brasileira, respondendo por $87 \%$ da produção nacional de mandioca, $70 \%$ da produção de feijão, $46 \%$ do milho, $38 \%$ do café, $34 \%$ do arroz, $58 \%$ do leite, $59 \%$ do plantel de suínos, $50 \%$ do plantel de aves, $30 \%$ dos bovinos e $21 \%$ do trigo. Além disso, ela ocupa cerca de $85 \%$ do total dos estabelecimentos rurais do país (4,4 milhões de estabelecimentos) em apenas $24,3 \%$ do total da área ocupada pelos estabelecimentos agropecuários brasileiros [2].

Apesar de a agricultura familiar ter sido historicamente pressionada, forte e negativamente, por um projeto de desenvolvimento pautado em uma produção agropecuária mecanizada e intensiva em insumos químicos, adequada à monocultura e às exportações, atores sociais - movimentos sociais, grupos de pesquisadores e outros - têm atuado na

\footnotetext{
${ }^{3}$ De acordo com Josué de Castro, em seu livro Geografia da Fome, publicado na década de 1970, a principal causa desse problema é a falta de acesso aos alimentos. Este decorre da precariedade do acesso a terra e da insuficiência de renda das famílias, que dificulta a obtenção de alimentos suficientes para a sobrevivência digna dos indivíduos.
}

tentativa de fortalecer esse segmento, advogando não só por políticas e programas orientados ao crédito e à assistência técnica e extensão rural, mas também pelo desenvolvimento de técnicas alternativas de produção na agricultura, como afirma Almeida [3]. É o caso de grupos de pesquisadores da Empresa Brasileira de Pesquisa Agropecuária (EMBRAPA), por exemplo, que advogam pela necessidade de conhecimento adequado à problemática e ao contexto da agricultura familiar. Esse "novo" conhecimento passa pelo entendimento de que a decisão desse segmento sobre o que e como produzir não é determinada apenas por fatores como preço e lucro, mas também por outras lógicas.

Assim, pesquisas sobre TS na agricultura, em especial, que visam a produção de alimentos no Brasil, são de fundamental importância para estimular um processo de desenvolvimento que vise tanto promover o acesso aos alimentos de qualidade por populações marginalizadas, bem como práticas de manejo sustentável dos recursos ambientais.

O presente artigo se circunscreve nessa perspectiva, como forma de contribuir para a compreensão sobre dinâmicas tecnológicas alternativas na perspectiva sociotécnica tendo como objeto de estudo a TS Produção Agroecológica Integrada e Sustentável (PAIS), que integra o projeto Tecnologia Social e Políticas Públicas na América Latina, desenvolvido conjuntamente pelo Grupo de Análise de Políticas de Inovação (GAPI), da Universidade Estadual de Campinas (UNICAMP), e pelo Instituto de Estudios sobre la Ciencia y la Tecnología (IEC/UnQ, Argentina), sob financiamento do International Development Research Centre (IDR, Canadá).

A tecnologia estudada é um programa financiado pelo Serviço Brasileiro de Apoio às Micro e Pequenas Empresas (SEBRAE), pela Fundação Banco do Brasil (FBB) e por alguns ministérios e tem como objetivo principal garantir a subsistência e a segurança alimentar dos beneficiários que possuem pequenas unidades rurais e suas familias e, de forma secundária, a geração de renda através da comercialização do excedente. Ela propõe a implantação de um conjunto de tecnologias para o manejo sustentável da produção, sem a utilização de produtos químicos e aproveitando recursos existentes na própria propriedade. Esse processo envolve assistência técnica prestada às famílias, fornecendo aprendizagens em gestão empreendedora e capacitações tecnológicas. 
De acordo com o programa, uma das capacitações compreende uma carga horária de 32 horas (teoria e prática), cujo propósito é criar as condições necessárias para que as famílias envolvidas no processo desenvolvam competências para refletir sobre sua atuação como promotor do desenvolvimento social, exercitar métodos, técnicas e procedimentos relacionados às atividades de agricultura orgânica, compreender os benefícios do consumo de alimento orgânico para o ser humano, aprender o conceito de sistema de irrigação, além dos princípios de sustentabilidade familiar e importância da integração dos animais ao sistema PAIS. O tempo de duração da reaplicação é definido pelos financiadores ou pelo tempo de execução do Projeto, ao qual é necessário que cada familia usuária tenha uma assistência técnica em agroecologia pelo menos por 18 meses.

Em 2004, a FBB, o SEBRAE e o Ministério da Integração Nacional, firmaram um Acordo de Cooperação, beneficiando 12 Estados (AL, BA, CE, GO, ES, PB, PI, RN, MG, MS, PE e SE), viabilizando atender 1.080 famílias em 36 municípios com a tecnologia PAIS. Entretanto, de acordo com a Fundação, já foram implantadas cerca de 10.000 unidades da TS, embora não haja comprovação documentada de quantas unidades permanecem ativas. Nessa parceria o SEBRAE ficou responsável pela articulação com os SEBRAEs/UF para seleção, capacitação de multiplicadores das familias beneficiadas e supervisão da atividade; a FBB viabilizou o kit de materiais para implantação do projeto no valor de $\mathrm{R} \$$ 3.500,00 e os Ministérios com recursos de custeios. Ressalta-se que outros ministérios também aportaram recursos, como o do Desenvolvimento Social e do Desenvolvimento Agrário.

O objetivo do artigo é analisar a dinâmica sociotécnica da PAIS, explorando especialmente alguns de seus limites percebidos a partir dos resultados obtidos pela pesquisa de campo. Parte desses limites se refere aos entraves de funcionamento ${ }^{4}$ da tecnologia analisada. E a outra parte se refere a um possível entrave da proposta mais ampla de TS. Vale ressaltar que este artigo não pretende esgotar o tema, apenas apontar elementos para aprofundar o debate sobre

\footnotetext{
4 O processo de "funcionamento" de uma tecnologia pode ser verificado a partir da viabilidade e da continuidade da tecnologia. Ou seja, a viabilidade da tecnologia é o resultado de um processo contínuo de construção de funcionamento por parte de grupos de atores vinculados ao desenvolvimento de um artefato ou política. Esses atores constantemente atribuem um significado positivo ou negativo à tecnologia que, a partir do consenso desses significados, normatizarão sobre a viabilidade da tecnologia ${ }^{[1]}$.
}

tecnologias para inclusão social e fornecer subsídios para as propostas dos atores sociais que advogam em prol da agricultura familiar.

Para alcançar este objetivo, a metodologia aplicada se baseou nos preceitos propostos pelos métodos científicos Pesquisa de Campo e Estudo de Caso, os quais prevêem a utilização de instrumentos de pesquisa como visitas de campo, entrevistas estruturadas e/ou semiestruturadas e observação participante. Os dados foram registrados em caderno de campo e em arquivo digital. Para aumentar o conhecimento acerca da PAIS foi necessário selecionar algumas experiências para visitação, sem aplicação de amostragem aleatória. Nesse sentido, foram indicadas pela FBB e SEBRAE unidades da experiência em Cristalina e Planaltina, em Goiás. Aproveitou-se a oportunidade para entrevistar os principais financiadores da TS e técnicos que prestam assessoria técnica aos agricultores.

O artigo está dividido em três seções, além desta apresentação. Na primeira seção, é abordado o debate acerca da TS e as suas principais características. Em seguida, as dinâmicas sociotécnicas do objeto de estudo (PAIS) são analisadas buscando detalhar o processo de co-construção da tecnologia - Kit PAIS - e do ambiente no qual ela é inserida. O objetivo desta seção é examinar aspectos da implantação do conjunto tecnológico, as relações sociais entre agricultores e assistência técnica e seu entorno sociotécnico. Com base na análise da segunda seção, são apontados na terceira - como considerações gerais - três limites de implantação e de funcionamento da PAIS e de TS.

\section{SOBRE TECNOLOGIA SOCIAL (TS)}

O conceito de TS é objeto de controverso debate entre grupos de natureza diversa, como movimentos sociais, comunidade acadêmica, Organizações Não-Governamentais (ONGs) e instituições públicas e privadas [4]. Jesus [5] destaca que grande parte dos conceitos propostos por tais grupos atribui à TS o papel de "atender às necessidades humanas" ou de ser veículo para a "transformação social" ou ainda "melhorar a qualidade de vida dos pobres". Serão discutidas essas expressões e seus conteúdos ao longo desta seção.

Antes de ser abordado o controverso conceito de TS, cabe retornar brevemente à própria concepção de tecnologia. Para Almeida [3], tecnologia é 
amplamente entendida como a aplicação sistemática de conhecimentos científicos e técnicos para a solução de tarefas práticas, em grande medida para realização da produção de mercadorias. No entanto, toda tecnologia está intrinsecamente ligada ao processo histórico, político, cultural e econômico no qual se insere. Em outras palavras, toda a tecnologia é socialmente concebida e desenvolvida. Portanto, a tecnologia não é neutra, isto é, ela incorpora conjuntos de valores e interesses que a justificam e fundamentam. Como colocam Almeida [3] e Dagnino [6], no capitalismo, enquanto fator de produção e sob a propriedade de determinada classe social, a tecnologia cumpre, entre outras funções, um papel fundamental de dominação social.

Se toda tecnologia é socialmente construída, o que significa então "Tecnologia Social"? Em primeiro lugar, como ressalta Dagnino et al. [7], a TS "não deve e nem precisa - ser entendida como um conceito". A expressão "Tecnologia Social" remete a um projeto particular de desenvolvimento tecnológico, cuja função é fomentar o processo de desenvolvimento econômico, político e cultural, enfim, um processo particular de desenvolvimento social.

Entre os elementos constitutivos desse projeto de desenvolvimento tecnológico social, destacam-se: elaboração de processos produtivos adequados a formas autogestionárias de organização do trabalho (e que superam a desigualdade de gênero e racial); elaboração de tecnologias e produtos ajustados ao contexto sócio-cultural em que estão inseridos e à lógica sistêmica do meio ambiente (manejo sustentável dos recursos); projeção das tecnologias com incorporação de conhecimentos tradicionais e científicos, com aproveitamento, quando necessário, da tecnologia convencional; apropriação das tecnologias pelos setores mais vulneráveis da classe trabalhadora de forma a estimular um processo de desenvolvimento com desconcentração de renda, fundamental aos países periféricos; fomento à apropriação coletiva dos meios de produção; e priorização do valor de uso da mercadoria produzida e da tecnologia que a produz (meio de produção) em detrimento do valor de troca (desmercantilização).

Trata-se evidentemente de um projeto ambicioso e quiçá utópico. As experiências concretas de TS não incorporam, portanto, todos os elementos aqui expostos, mas devem vislumbrar uma determinada "transformação social" que permita a superação da sociabilidade capitalista. Nesse sentido, a TS não é um "fim em si", mas "uma ferramenta para construir outra sociedade" [7]. Entretanto, tal transformação requer um engajamento político consciente de seus objetivos últimos, bem como dos limites impostos pelas condições materiais e ideológicas da realidade concreta (possibilidades atuais). Enfatiza-se que os diferentes grupos que se somam ao "movimento pela TS" possuem um espectro extremamente variado de interesses e visões ideológicas, nem sempre corroborando com a transformação social aqui proposta. Para Jesus [5], uma parcela significativa dos grupos que reivindicam fomento à TS a compreendem como um instrumento para amenizar os efeitos deletérios do capitalismo.

A TS visa à satisfação das necessidades mais básicas das frações populares marginalizadas, seja por meio do próprio bem produzido (ex: TS voltadas à segurança alimentar), seja pela venda da mercadoria produzida. Em geral, as duas opções ocorrem conjuntamente, como é o caso da PAIS. A primeira opção é a menos mercantilizada, já que o fim último do processo produtivo é a própria utilização ou consumo do produto pelo seu produtor (o que não caracteriza o bem como mercadoria). Entretanto, dada a impossibilidade de se produzir tudo o que se necessita no capitalismo, os grupos que adotam a TS comercializam seus produtos para adquirirem outras mercadorias que satisfaçam suas necessidades. Dessa forma, a segunda opção, a venda da mercadoria produzida por meio da TS, configura-se como necessidade imediata.

Entretanto, para ser caracterizada como "social", a tecnologia deve exaltar seu valor de uso, qual seja, de ser o meio para a produção de bens cujo objetivo é satisfazer as necessidades mais básicas de parcelas marginalizadas da classe trabalhadora. Nesse sentido, para Otterloo ${ }^{[8]}$ um dos aspectos centrais é o controle social da tecnologia, tanto no que se refere à sua produção como apropriação e possibilidades de recriação. A socialização das TS entre movimentos populares e de classe pode ser considerada, portanto, como pressuposto para sua própria constituição.

As questões sobre apropriação coletiva da tecnologia e o valor de uso da tecnologia, inclusive da TS, e as características da TS apontadas ao longo desta seção permitirão uma melhor compreensão da dinâmica sociotécnica da TS PAIS. 
A próxima seção tem como objetivo examinar aspectos da implantação do conjunto tecnológico da TS PAIS, as relações sociais entre agricultores e assistência técnica e seu entorno sociotécnico. Para isso, a metodologia utilizada foi Pesquisa de Campo e Estudo de caso, os quais prevêem a utilização de instrumentos de pesquisa como visitas de campo, entrevistas estruturadas e/ou semiestruturadas e observação participante. Os dados foram registrados em caderno de campo e em arquivo digital. A seguir, são descritos os resultados da pesquisa de campo.

\section{COMPREENDENDO O PROCESSO DA DINÂMICA SOCIOTÉCNICA DA PRODUÇÃO AGROECOLÓGICA INTEGRADA E SUSTENTÁVEL (PAIS)}

A TS PAIS se configura por meio da integração entre processos e artefatos. Tem como principal componente tecnológico um mix de tecnologias voltadas ao processo produtivo de pequenas e médias propriedades rurais. Tais tecnologias buscam manejar os recursos da propriedade de forma sustentável e integrada, segundo os preceitos da Agroecologia. Nesse sentido, o mix de tecnologia é composto por design circular do plantio (horta circular), sistema de irrigação com eficiência de água, adubação verde e composto orgânico e galinheiro central (estrutura circular).

Para que uma propriedade rural receba esse mix de tecnologias (doravante mencionado como "kit PAIS") é preciso que cumpra alguns requisitos. O primeiro se refere às condições socioeconômicas do agricultor que deve, preferencialmente, se encontrar em condição de familia socioeconomicamente vulnerável, com uma ou mais pessoas disponíveis para o trabalho manual e de comercialização, com disposição para as atividades rurais. Entretanto, embora esse seja o perfil desejado pelos financiadores, as propriedades visitadas apontaram outros elementos, como, por exemplo, a predominância de pessoas que nasceram no meio rural, viveram grande parte de sua vida adulta no meio urbano e regressaram para o meio rural.

Nas propriedades visitadas, o trabalho diário na área de PAIS é realizado por uma pessoa, que, durante 18 meses, recebe assistência técnica de consultores contratados pelas instituições financiadoras da TS. A carga horária de trabalho é de até 12 horas diárias, e embora apenas uma pessoa da propriedade seja responsável pela unidade produtiva, verificou-se que, eventualmente, membros da família auxiliam o trabalho. Não foram encontrados casos de contratação de trabalho de terceiros.

O processo de implantação da PAIS passa por três momentos, relacionados à seleção e capacitação das pessoas/familias que irão participar do programa, à criação de ambiente para instalação das tecnologias e, por fim, à implantação do kit PAIS. A Figura ilustra os momentos e suas atividades correspondentes.

A seleção das propriedades ocorre por meio de entrevistas com os agricultores, que podem ser realizadas tanto por agentes das instituições financiadoras quanto por organizações do terceiro setor atuantes na área da agricultura e/ou instituições de extensionismo rural. A atividade que segue é executada, na maioria dos casos relatados, pelo primeiro tipo de organização supracitada. O curso de capacitação ocorre geralmente em finais de semana e são realizados em propriedades rurais pré-selecionadas.

Já a criação de ambiente para o kit tecnológico se refere ao estudo da viabilidade de implantação das tecnologias. Realizado por técnicos das instituições contratadas para executar a assessoria ao programa, conta com a participação do agricultor ou agricultora durante todo o processo. Nas experiências visitadas, o momento de implantação do kit tecnológico é realizado em sua maior parte pelo próprio agricultor, que pode contratar alguém para auxiliá-lo na atividade, sendo que, em alguns momentos, o técnico manipula ferramentas, como enxadas e sulcadores. No caso das experiências visitadas, nenhuma delas contratou terceiros para implantar o kit PAIS. É percebido, portanto, uma forte participação do agricultor na implantação da tecnologia e assim também na apropriação desta.

As experiências visitadas contavam com pouco tempo de vida o que não permitiu verificar a ocorrência da atividade "associativismo, cooperativismo e empreendedorismo individual". Verificou-se somente que poucos comercializam para pessoas de suas comunidades. Nesse sentido, pode-se inferir que a dificuldade em comercializar o excedente da produção está relacionada à baixa capacidade associativa em redes de agricultores e de participação em redes de comercialização por parte dos beneficiários da TS.

Nesse sentido, a viabilidade econômica das experiências está na possibilidade de comercialização 
para programas do Governo Federal. Além dos tradicionais meios de comercialização (como feiras e mercados), a PAIS possui um potencial de expansão a partir de dois mecanismos, criado pelo Governo Federal, que favorece a compra de alimentos produzidos por trabalhadores rurais da Agricultura Familiar. Eles são: Programa de Aquisição de Alimentos (PAA - Art. 19 da Lei no 10.696 e Decreto no 6.447, de 2008) e Lei federal 11.974/2009, que, segundo regra, prevê que 30\% dos recursos repassados pela União para os Estados e Municípios relativos à alimentação escolar, por meio do Fundo Nacional de Desenvolvimento para a Educação (FNDE), devem ser aplicados na compra de produtos provenientes da agricultura familiar.

Figura. Fluxograma do processo de implantação da Produção Agroecológica Integrada e Sustentável (PAIS)

\section{Implantação da Produção Agroecológica Integrada e Sustentável (PAIS)}
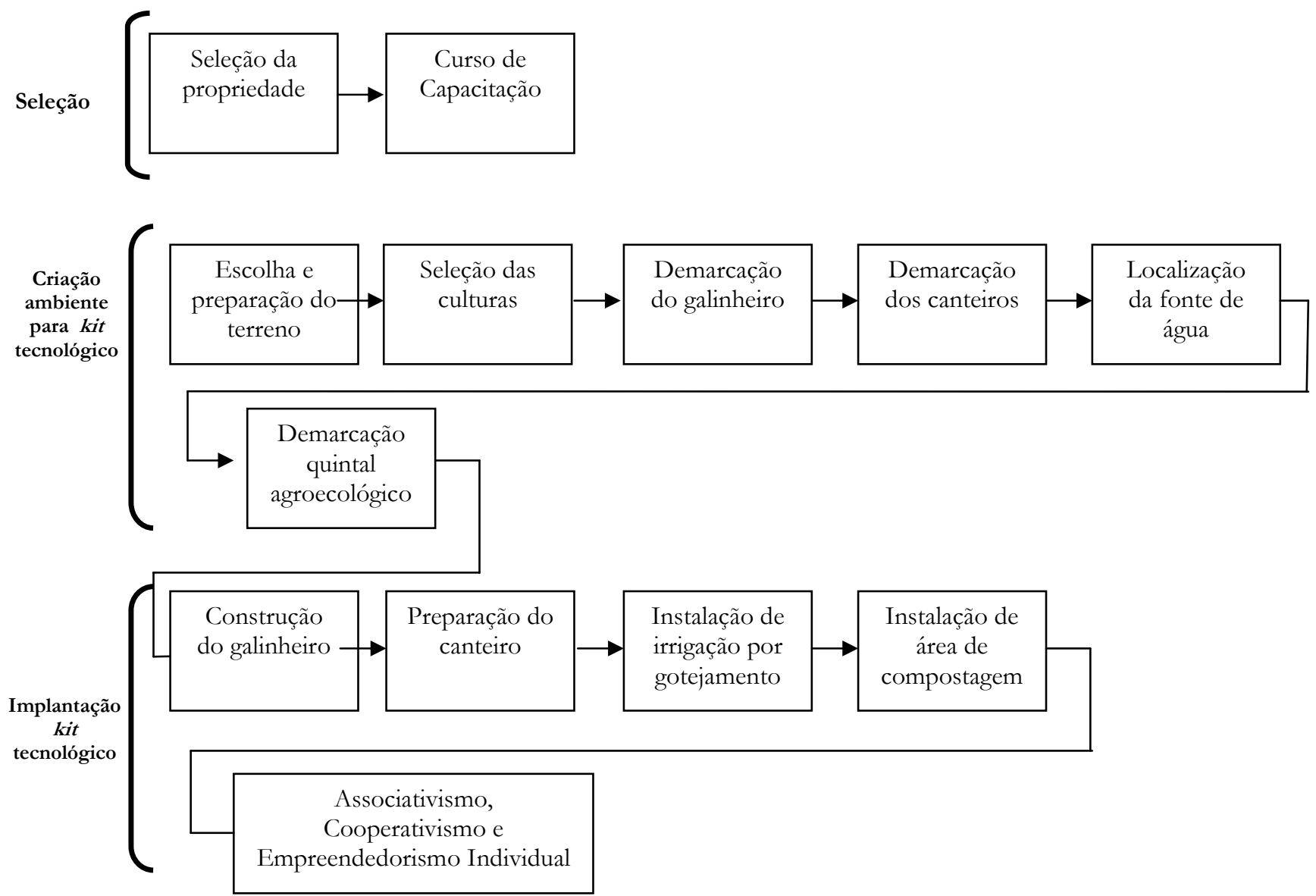

Fonte: Elaboração dos autores. 
Os agricultores beneficiários da PAIS têm nessas iniciativas de compra governamental um forte respaldo de continuidade da tecnologia implantada e, portanto, do funcionamento da mesma. Entretanto, a comercialização dos produtos agroecológicos por parte desses agricultores fica condicionada à obtenção de certificação desses produtos, que é obrigatório por Lei. A dificuldade de acesso à certificação é um dos limites de continuidade/funcionamento da PAIS, como será visualizado na próxima seção.

No que tange à sustentabilidade ambiental, o kit PAIS foi elaborado a partir dos conceitos agroecológicos, visando a produção de alimentos orgânicos. Nesse sentido, foi observada na pesquisa de campo a preservação desses conceitos, através das seguintes práticas: não utilização de adubos químicos ou agrotóxicos; irrigação por gotejamento para melhor aproveitamento da água; manejo biológico das pragas; e otimização do espaço cultivado e diversificação das culturas. Apesar de a PAIS prever um galinheiro central fechado, foram observadas experiências em que as galinhas eram criadas soltas. As sementes, no entanto, não são necessariamente crioulas. Além disso, não foram observados sistemas de captação de água de chuva nas unidades visitadas.

Alguns elementos importantes para $\mathrm{O}$ funcionamento sistêmico e integrado da PAIS devem ser pontuados, como a compostagem, a qual aproveita o excremento das galinhas e os restos orgânicos da produção e do entorno (folhas, ossos) e o viveiro de mudas, que possibilita a reprodução sistêmica dos cultivos e uma relativa autonomia do agricultor frente à aquisição de sementes. Complementarmente, é comum a implementação conjunta da PAIS com o sistema de esgoto sanitário "Fossa Séptica Biodigestora", também promovida pela FBB e SEBRAE.

Os cursos de capacitação reforçam a importância da produção e do consumo de produtos orgânicos para a saúde e meio ambiente. Os agricultores entrevistados demonstraram conscientização e um grande esforço de incorporação de práticas sustentáveis. Como mencionado previamente, algumas famílias já possuíam uma tradição no campo, com cultura mais ligada ao ambiente rural em que o plantio de hortas sempre esteve presente. Entretanto, o plantio totalmente orgânico e em forma circular, bem como o sistema de irrigação se apresentaram em geral como novidade nas unidades visitadas. Não foram relatadas mudanças substantivas nos hábitos alimentares, mas sim uma diversificação da alimentação e preferência por consumo de produtos orgânicos.

Para finalizar a análise da PAIS, Thomas et al. [9] sugerem três elementos para olhar o processo de coconstrução de elementos heterogêneos da dinâmica sociotécnica: relação problema-solução, relações usuário-produtor e processos de construção de "funcionamento" de uma tecnologia.

O primeiro - relação problema-solução - se conformou a partir da necessidade em atuar sobre a problemática pobreza rural e da experiência prévia de uma das instituições financiadoras. A "problemática" Insegurança Alimentar e Nutricional no campo, aliada a ocorrência de êxodo rural, é verificada principalmente em regiões carentes do Brasil. A fim de intervir sobre essa problemática, um técnico do SEBRAE propôs uma TS (Projeto Mandalla) de fácil reaplicação como "solução". Esta foi a escolhida por causa da forte pressão do ator SEBRAE, que passaria a ter uma atuação de destaque frente a essa problemática e comporia, enquanto um ator importante, a estratégia de combate à fome do Governo Federal.

A tecnologia analisada - o kit PAIS - surge como uma solução secundária, a partir do reprojetamento da "Mandalla", tecnologia para a qual havia sido requerida a proteção de modelo de utilidade (tipo de patente) junto ao Instituto Nacional de Propriedade Industrial, dificultando o potencial de reaplicação em larga escala da tecnologia. Com o intuito de não interferir significativamente na dinâmica já consolidada no Projeto Mandalla, o kit PAIS foi desenhado contemplando características semelhantes à da Mandalla. Nesse sentido, não foi verificada uma tentativa, por parte grupos sociais relevantes, de readequar a dinâmica problema-solução.

O segundo elemento - relação usuárioprodutor - busca verificar a participação do usuário da tecnologia na conformação ou readequação da mesma. Observa-se que a participação do agricultor na conformação da "solução" do problema foi nula.

Já no momento da reaplicação da tecnologia, foi verificada a influência do agricultor junto ao técnico no processo de readequação do seu kit PAIS. Um exemplo da interação entre esses dois atores foi a adequação dos viveiros das galinhas e no cultivo e armazenamento de mudas. Entretanto, essa adequação não foi incorporada em um possível reprojetamento do kit PAIS. Apesar desse reprojetamento não ter 
ocorrido, pode-se inferir que - em um processo contínuo de aprendizagem e melhoria - os técnicos foram incorporando essas adequações e as implementando.

O processo de "funcionamento" da tecnologia - terceiro elemento - foi verificado a partir de três óticas: a dos financiadores, a dos técnicos e a do agricultor. No que se refere aos financiadores, a tecnologia passou a "funcionar" no momento em que ela se tornou uma marca/logo, passível de captação de recursos junto aos ministérios, e de replicação em larga escala com a estruturação de um “kit”. Para os técnicos, ela vem funcionando tendo em vista a rede de instituições de consultores participantes do processo que se conformou em volta da tecnologia e de sua reaplicação. Ou seja, uma "possível" mão-de-obra ociosa foi inserida no processo. De acordo com o "usuário", a tecnologia só funcionou se o "usuário" da tecnologia passou a maior parte de sua vida no campo e se houve, portanto, uma identificação dele com a relevância da proposta e, por conseguinte, apropriação dos princípios da agricultura agroecológica. Caso contrário, a funcionalidade da tecnologia se torna baixa.

A seguir, alguns limites da tecnologia - um importante elemento da análise sociotécnica - serão analisados. O objetivo é apresentar possíveis barreiras que enfraquecem o processo de funcionamento da tecnologia.

\section{ALGUNS LIMITES DA TECNOLOGIA SOCIAL (TS)}

Ao analisar a PAIS, o presente trabalho visualizou possíveis limites enfraquecedores do processo de "funcionamento" dessa tecnologia. Dentre os limites encontrados, serão abordados três problemáticas: a da certificação da produção orgânica e o processo de comercialização; a da regularização da titularidade da terra; e, principalmente, $\mathrm{O}$ da propriedade intelectual.

\section{A questão da certificação da produção orgânica e da comercialização}

$\mathrm{O}$ primeiro limite se refere à obrigatoriedade da certificação da produção orgânica para comercialização desses produtos no Brasil. De acordo com as entrevistas, grande parte dos agricultores que utilizam a tecnologia "kit PAIS" não tem sua produção certificada. Por conta disso, na maioria dos casos, os agricultores acabam por comercializar sua produção a preço comum, e não com o acréscimo de quase $40 \%$ relativo aos produtos serem orgânicos ${ }^{5}$. Ou, também, acabam por entregar sua produção aos atravessadores para comercialização. Como muitos agricultores ainda não conseguiram se integrar a redes de comercialização, eles permanecem "reféns" dos preços dos atravessadores.

A certificação de produtos orgânicos no Brasil passou a ser obrigatória em 2003 com a instituição da Lei no 10.831, de 23 de setembro de 2003. Esta lei sancionou o sistema orgânico de produção agropecuária, englobou dentro desse sistema os conceitos ecológico, biodinâmico, natural, regenerativo, biológico, agroecológico, permacultura e outros ${ }^{6}$, e instituiu - para comercialização dos produtos orgânicos - a obrigatoriedade da certificação deles.

O agricultor tem acesso a essa certificação através de três mecanismos: 1. Certificação por Auditoria; 2. Sistema Participativo de Garantia (SPG); 3. Controle Social na Venda Direta [10]. Em relação ao primeiro, a certificadora pública ou privada credenciada junto ao Ministério da Agricultura, Pecuária e Abastecimento (MAPA) emite o certificado após a realização de auditoria da produção e do estabelecimento, conforme critérios pré-estabelecidos pelos regulamentos brasileiros. Os custos desses serviços são arcados pelos agricultores. Por conta disso, o acesso aos serviços dessas certificadoras fica restrito ao grupo de agricultores familiares mais capitalizados. Este público não é o mesmo do “kit” PAIS.

O segundo mecanismo de certificação está relacionado a um processo coletivo de certificação de grupos de agricultores familiares, de projetos de assentamento, de quilombolas, de ribeirinhos, de indígenas e de extrativistas. A formação do Sistema Participativo de Garantia (SPG) ocorre a partir de um grupo de agricultores, fornecedores e consumidores, que é reconhecido como Membros do Sistema, e pelo Organismo Participativo de Avaliação da Conformidade (OPAC), que é uma organização com personalidade jurídica própria que corresponde às

\footnotetext{
${ }^{5}$ Campanhola \& Valarini ${ }^{[12]}$ colocam que "os preços dos produtos orgânicos no varejo são, em média, entre $30 \%$ e $40 \%$ maiores que os seus similares convencionais. O trigo chega a custar $200 \%$ acima do preço do produto convencional, enquanto o açúcar atinge até $170 \%$ a mais" (p. 74).

${ }^{6}$ Esse processo de aglutinamento dos conceitos em apenas orgânico vem sendo debatido por vários autores que analisam esse processo como uma forma de despolitizar conceitos como o caso do agroecológico.
} 
certificadoras do primeiro mecanismo [10]. Esse mecanismo nasceu como uma forma alternativa ao sistema formal de certificação por auditoria externa. A Região Sul do Brasil, especialmente a Rede Ecovida de Agroecologia, desenvolveu a iniciativa denominada de "Certificação Participativa" [11].

Apesar desse mecanismo também, em alguns casos, ser custeado pelos agricultores, sua principal especificidade está na prerrogativa do agricultor fazer parte de uma rede ou associação de agricultores. Em outras palavras, esse mecanismo está mais adequado para os agricultores familiares que estão organizados em associações ou cooperativas. Assim como no primeiro mecanismo, as associações ou cooperativas precisam prover de um recurso para custear as visitas que, na maioria dos casos, não possuem.

No que se refere ao último mecanismo, a legislação abriu uma exceção à obrigatoriedade da certificação de produtos orgânicos. Os agricultores familiares poderão vender seus produtos sem certificação de forma direta aos consumidores finais. Esses agricultores precisam estar vinculados a uma organização, denominada de Organização de Controle Social (OCS). Esta deve ser formada por um grupo, associação, cooperativa ou consórcio, com ou sem personalidade jurídica, de agricultores familiares. Após a formação, a OCS deverá pedir o seu credenciamento junto às Superintendências Federais de Agricultura do Ministério da Agricultura. O cadastro também pode ser feito em outro órgão fiscalizador conveniado do Governo Federal, Estadual ou do Distrito Federal.

Assim como os outros mecanismos, esse também possui uma barreira específica relativa ao processo de certificação. Enquanto no primeiro mecanismo a barreira é financeira e no segundo é de capacidade associativa, a barreira no terceiro mecanismo se refere à prerrogativa da participação dos agricultores em redes de comercialização. Campanhola \& Valarini [12] ressaltam a importância da inserção dos pequenos agricultores nas redes de comercialização de produtos, mas também ressaltam que o alcance dessa inserção está ligado ao nível de organização desses agricultores em associações ou cooperativas.

Tendo em vista o perfil do beneficiário da ação PAIS - agricultor com produção majoritariamente de subsistência e pouco articulado, é possível inferir a dificuldade dele em obter a certificação através de qualquer um dos mecanismos. Aliado a isso, essa dificuldade gera entraves na possível obtenção de crédito e também na comercialização, especialmente para o próprio poder público.

Os custos de certificação e de acompanhamento das exigências da certificação são ainda um gargalo para a geração de renda, um dos objetivos da ação PAIS, mas também para a produção de orgânicos por parte dos agricultores familiares ${ }^{[12] . ~}$

Além dessas questões, os critérios da certificação também são um limite para a continuidade da produção de orgânicos pelos agricultores familiares. Isso porque, conforme destacam Rigby \& Cáceres ${ }^{7}$, o estabelecimento de padrões de certificação nacionais e internacionais atrairá as grandes organizações para esse segmento de produção. Para que isso não ocorra, é necessário que as iniciativas locais de certificação sejam incentivadas, como a possibilidade de se obter o selo por meio do Sistema Participativo de Garantia. Ademais, é também necessário repensar os próprios critérios de certificação. Está muito mais associada à critérios sociais e ambientais, como o caso do "comércio justo", do que em critérios internacionais, sob os quais eles estão submetidos.

\section{A questão da regularização da titularidade da terra}

A problemática da irregularidade da posse da propriedade é um dos limites do processo de "funcionamento" da ação PAIS. Essa situação irregular nos remete ao padrão de ocupação ancestral da terra (quilombolas, ribeirinhos, extrativistas), à falta de acesso aos instrumentos jurídicos de regularização pelo seu alto custo (ocupantes da sua própria terra não regularizados, ocupantes de terras particulares portadores de direito de usucapião) e à própria incapacidade do Estado em trabalhar essas questões [13].

A falta de titulação da terra, além de ser um dos principais fatores de instabilidade e insegurança para os agricultores, dificulta o acesso às políticas públicas e aos recursos dos programas de Governo, especialmente aqueles relacionados a programas de crédito, de organização associativa, de fomento à comercialização, de assistência técnica e outros. E esse é o caso de muitos beneficiários da PAIS.

\footnotetext{
7 Rigby D, Cáceres D. Organic farming and the sustainability of agricultural systems. Agricultural Systems, Amsterdam, 2001, 68:21-40 apud Campanhola \& Valarini [12].
} 
Em relação à própria incapacidade do Estado em trabalhar essas questões, destaca-se o esforço do Programa de Cadastro de Terras e Regularização Fundiária do Governo Federal. Este tem como objetivo regularizar a situação jurídica de posseiros, agricultores familiares e populações tradicionais com expedição de títulos de domínio ou concessão de direito real de uso. Ele consiste em uma ação que busca integrar a regularização da propriedade e o acesso dos proprietários dos imóveis rurais ao crédito rural e a assistência técnica. O programa conta com três etapas para a regularização: o cadastramento, o georreferenciamento e a destinação/regularização das posses. Essas etapas requerem o estabelecimento de convênios com Estados para efetuar essa regularização.

Entretanto, em 2010 o programa alcançou apenas $37 \%$ da meta prevista para o período, o que deveu-se, principalmente, ao atraso nas atividades de georreferenciamento e titulação ${ }^{[14]}$. Ou seja, é visível a baixa capacidade do Estado em tratar dessa questão visà-vis a demanda.

A importância da regularização da titularidade da terra para os agricultores familiares está na possibilidade de usufruir dos instrumentos de política pública, que lhes são negados. Esses instrumentos possibilitarão, no caso dos beneficiários da PAIS, a expansão da produção e da geração de renda.

\section{A questão da propriedade intelectual e Tecnologia Social (TS): um olhar a partir da Produção Agroecológica Integrada e Sustentável (PAIS) e Projeto Mandalla}

A partir da experiência de surgimento da PAIS, esta subseção busca uma reflexão inicial sobre o tema da propriedade intelectual e TS, apontando que a proteção monopolística de TS por meio de direitos de propriedade intelectual se configura como uma desvinculação ideológica aos preceitos orientadores da TS, expostos previamente neste artigo. Essa subseção tem como objetivo subsidiar e estimular - e não esgotar - essa reflexão.

Um elemento do entorno sociotécnico que foi determinante para a construção da PAIS está relacionado a conflitos referentes à propriedade intelectual. O conjunto de tecnologias que atualmente a constitui teve suas origens em uma iniciativa similar prévia denominada de Projeto Mandalla, financiada pela FBB e SEBRAE, que foi objeto de depósito de patente junto ao Instituto Nacional da Propriedade Intelectual (INPI).

O "Sistema Mandalla de Produção" idealizado por Willy Pessoa Rodrigues, ex-funcionário do SEBRAE/Paraíba e atual coordenador da Agência Mandalla $^{8}$ - consiste em um sistema circular de plantio orgânico ao redor de um tanque central em formato cônico (abastecido por cisterna, açude ou riacho próximo), em que são criados peixes e patos. O tanque possui também a função de armazenar a água, que é bombeada para os canteiros que o circundam. Acoplados às mangueiras que conduzem a água aos canteiros, cotonetes são utilizados como aspersores.

O Projeto Mandalla foi contemplado com o prêmio de TS da FBB em 2003, mesmo ano de fundação da Agência Mandalla. Em 2004, a FBB e o SEBRAE financiaram R $\$ 4$ milhões para a implantação de 920 unidades de Mandalla em 80 municípios de 11 Estados, sendo os recursos destinados à instalação do sistema produtivo, cursos de capacitação ministrados pela Agência Mandalla e acompanhamento técnico do SEBRAE. De acordo com Borges [15], em setembro de 2004, unidades de Mandalla já haviam sido instaladas em nove Estados brasileiros.

No entanto, um pedido de patente de Modelo de Utilidade 9 para o Projeto Mandalla foi depositado junto ao INPI em 2004, o que desestimulou a FBB e o SEBRAE a darem continuidade à iniciativa em 2005, já que a proteção patentária, caso concedida, acarretaria em pagamento de royalties ao titular da patente, encarecendo substancialmente os custos para replicação do kit tecnológico em larga escala. Tal fato levou a Agência Mandalla a buscar outros financiadores, como a transnacional Bayer CropScience, que desde 2005 destina verbas a fundo perdido para o Projeto.

Nesse contexto, o engenheiro agrônomo senegalês Aly N'Diaye foi convidado pela FBB e

\footnotetext{
8 Para mais informações sobre a Agência Mandalla, consultar página eletrônica da instituição: http://www.agenciamandalla.org.br/index.php.

9 A patente de Modelo de Utilidade protege uma nova forma ou disposição de um objeto já conhecido de uso prático suscetível de aplicação industrial. A nova forma ou disposição deve promover melhoramentos funcionais na utilização do objeto, que pode ser resultado da combinação de elementos conhecidos, desde que envolva ato inventivo. O tempo de proteção de patente de modelo de utilidade previsto na Lei da Propriedade Industrial 9279/96 é de 15 anos. Depositado em 06/07/2004, o pedido de patente de modelo de utilidade para o Projeto Mandalla (Pedido № MU 8402415-1) foi indeferido pelo INPI em 14/06/2011. Em fevereiro de 2012, o depositante solicitou recurso contra o indeferimento, objetivando o reexame do pedido de patente. O processo ainda está em andamento.
} 
SEBRAE para elaborar tecnologias de produção agroecológica de baixo custo de reaplicação, viabilizando portanto um projeto de segurança alimentar de âmbito nacional. O mix de tecnologias projetadas por ele atualmente constituem a PAIS. A diferença da PAIS em relação a Mandalla está na substituição do tanque de peixes por um galinheiro central e do sistema de irrigação de aspersores de cotonetes pela irrigação por gotejamento. Além disso, o SEBRAE [16] ressalta que N'Diaye adicionou o quintal agroecológico ao projeto. As etapas necessárias para a implantação da PAIS, incluindo a seleção das familias, os cursos de capacitação e o acompanhamento técnico, permaneceram muito similares ao previsto no Projeto Mandalla.

Entretanto, técnicos que atuavam no Projeto Mandalla e que, atualmente, trabalham com a PAIS relataram avanços técnicos principalmente no sistema de irrigação por gotejamento, que prescinde de grandes volumes de água e energia elétrica, antes necessários para manutenção do tanque e da bomba que impulsionava a água para os canteiros.

A tentativa de patenteamento do Projeto Mandalla - além de ter sido determinante para a constituição da dinâmica sociotécnica do kit PAIS expõe a necessidade de uma reflexão sobre a apropriação privada da TS por meio de direitos de propriedade intelectual. Os seguintes questionamentos se fazem muito pertinentes: Como os conhecimentos incorporados a um conjunto tecnológico cujo objetivo é garantir a segurança alimentar da população rural brasileira pode ser a propriedade privada de um indivíduo ou instituição, que reivindica uma renda de monopólio pelo uso de tais conhecimentos? Ou ainda, como tal conjunto tecnológico pode ser entendido como uma TS?

Há uma tendência recente de intensificar a mercantilização das TS, utilizando-se da retórica de "melhorar a qualidade de vida dos pobres". Segundo Oliveira [17], o termo "mercantilização" é um neologismo que teve sua origem no período neoliberal, em que houve um "revigoramento da propensão capitalista a transformar tudo em mercadoria" (p. 84). Não por coincidência, regimes rígidos internacionais de direitos de propriedade intelectual, os quais privatizam conhecimentos referentes à natureza, cultura e à tecnologia surgem nessa época.
Reconhece-se, no entanto, que a construção de TS, como força produtiva, se dá dentro da lógica capitalista, o que impõe traçar certas estratégias para que não sejam apropriadas, através dos mecanismos jurídicos de propriedade intelectual, pelos grandes grupos industriais ou outros atores que visam usufruir do monopólio da tecnologia. Esse risco é real para alguns setores de TS, como por exemplo, de medicamentos fitoterápicos baseados em conhecimentos tradicionais sobre plantas medicinais (biopirataria), que pode inclusive abarcar nichos elitizados de mercado.

Nesse sentido, propõe-se a utilização de mecanismos defensivos como a publicação e publicização de artigos sobre a tecnologia - o que impede, segundo a lei, seu patenteamento, ou até mesmo o patenteamento das tecnologias e o estabelecimento de licenciamento não exclusivo, que possibilitaria a apropriação e potencial recriação da tecnologia apenas pelos grupos ligados à TS, em detrimento da exploração mercantilizada da tecnologia. Néder ${ }^{[18]}$ pontua que diversos autores argumentam que os conhecimentos tradicionais demandam uma construção de um regime sui generis de "direito intelectual coletivo", baseado no reconhecimento e fortalecimento do livre intercâmbio de informações. Considera-se que tal é a necessidade também das TS, bem como outros bens intelectuais ligados à cultura $\mathrm{e}$ desenvolvimento científico. Salienta-se que é de extrema relevância que os grupos ligados à TS incorporem em suas agendas um debate aprofundado sobre TS e propriedade intelectual.

\section{CONSIDERAÇÕES FINAIS}

Buscou-se apresentar neste artigo a importância da TS, aliada a ações sociais coletivas, enquanto instrumento para solucionar complexos problemas sociais. Em particular, abordou-se a TS PAIS - técnica agroecológica associada à agricultura familiar, como forma de superar a Insegurança Alimentar e Nutricional.

Foi realizada, a partir da PAIS, uma análise sociotécnica da tecnologia, a qual exige uma reflexão sobre como se deu o processo de construção do problema e sua solução pelos atores envolvidos com a TS, bem como sobre sua dinâmica de implantação e funcionamento, tendo como pano de fundo elementos técnicos, sociais e institucionais. 
A análise sociotécnica da PAIS nos permitiu identificar alguns limites para o funcionamento e continuidade da TS, a saber: (a) dificuldade de obtenção da certificação de produtos orgânicos (obrigatória no Brasil) por parte de agricultores familiares; (b) falta de acesso aos instrumentos jurídicos de regularização da titularidade da terra, que além de causar uma insegurança aos agricultores familiares, os impede de participar em diversas políticas públicas; (c) por fim, o terceiro limite relaciona-se com o tema mais amplo da propriedade intelectual de TS, já que a análise da construção sociotécnica da PAIS nos indicou que sua origem remonta ao Projeto Mandalla, que foi objeto de pedido de patente, limitando a difusão e promovendo a mercantilização da tecnologia Mandalla, algo contrário à proposta da TS.

No que se refere à primeira limitação, atrelado ao perfil do beneficiário da PAIS ser majoritariamente de subsistência, uma forma de minimizá-la está na perspectiva de estruturar e incentivar iniciativas locais de certificação, como a possibilidade de se obter o selo por meio do Sistema Participativo de Garantia.

Em relação à segunda limitação, ainda que o Programa de Cadastro de Terras e Regularização Fundiária do Governo Federal não venha alcançando metas ambiciosas, ele reconhece a falta de titulação da terra como um dos principais fatores de instabilidade e insegurança para os agricultores, dificultando o acesso às políticas públicas e aos recursos dos programas de Governo, especialmente aqueles relacionados a programas de crédito, de organização associativa, de fomento à comercialização, de assistência técnica e outros. Neste sentido, vale recomendar que seria importante que as associações dos agricultores familiares, assim como os movimentos sociais, passassem a exercer maior pressão junto ao governo para que o programa avance significativamente.

Por fim, a terceira limitação vai de encontro com a perspectiva das TS, ou seja, conhecimento aberto e pautado nas necessidades locais e sociais. Verifica-se uma tendência em mercantilizar as TS a partir da institucionalização dos mecanismos jurídicos de propriedade intelectual. Esse risco é real para setores de TS vinculados aos medicamentos fitoterápicos baseados em conhecimentos tradicionais sobre plantas medicinais (biopirataria), que pode inclusive abarcar nichos elitizados de mercado. Nesse sentido, uma saída seria a utilização de mecanismos defensivos como a publicação e a publicização de artigos sobre experiências de TS - o que impede, segundo a lei, seu patenteamento, ou até mesmo o patenteamento das tecnologias e o estabelecimento de licenciamento não exclusivo, que possibilitaria a apropriação e potencial recriação da tecnologia apenas pelos grupos ligados à TS, em detrimento da exploração mercantilizada da tecnologia.

\section{REFERÊNCIAS}

[1] Toledo VM. Agroecologia, sustentabilidad y reforma agraria: la superioridad de la pequeña producción familiar. Agroecol e Desenv Rur Sustent. 2002;3(2):27-36.

[2] Instituto Brasileiro de Geografia e Estatística [Brasil]. Censo Agropecuário 2006 - Agricultura Familiar. Brasília (DF): IBGE; 2006 [acesso em 10 fev 2014]. Disponível em: http://www.ibge.gov.br/home/estatistica/economia/agrope cuaria/censoagro/2006/default.shtm

[3] Almeida MLP. A apropriação do conhecimento público pelo setor privado na relação universidade-empresa: um estudo a partir do caso da UNICAMP [tese]. Campinas: Faculdade de Educação; 2001.

[4] Rutkowski J. Sustentabilidade de empreendimentos solidários: que papel espera-se da tecnologia. In: Lianza S, Addor F. (Org.). Tecnologia e Desenvolvimento Social e Solidário. Porto Alegre: UFRGS Editora; 2005.

[5] Jesus VMB. Análise do Sistema de Monitoramento e Avaliação da Rede de Tecnologia Social [dissertação]. São Carlos: Centro de Ciências Exatas e Tecnologia, Universidade Federal de São Carlos; 2010.

[6] Dagnino R. Neutralidade da ciência e determinismo tecnológico. Campinas: Editora Unicamp; 2008.

[7] Dagnino R, Brandão FC, Novaes HT. Sobre o marco analítico-conceitual da Tecnologia Social. In: Dagnino R. (Org.). Tecnologia Social: ferramenta para construir outra sociedade. Campinas: Ed. Komedi; 2010.

[8] Otterloo A. A Experiência da Rede de Tecnologia Social (RTS). In: Otterloo et al. (Org.). Tecnologias Sociais: Caminhos para a sustentabilidade. Brasilia (DF): Gráfica Brasil; 2009.

[9] Thomas H, Fressoli M, Aguiar D. Procesos de construcción de "funcionamiento" de Organismos Animales Genéticamente Modificados: El caso de la vaca transgénica clonada (Argentina 1996-2006), Convergencia. 2006;13(42):153-180. 
[10] Ministério da Agricultura, Pecuária e Abastecimento [Brasil]. Relatório de Gestão do Exercício de 2010. Brasília: MAPA; 2011 [acesso em 09 fev 2014]. Disponível em: http://www.agricultura.gov.br

[11] Medaets J, Pettan K. Legislação e normas para a certificação de produtos orgânicos: políticas públicas e garantias da qualidade. In: Küster A, Martí JF. (Org.). Agricultura familiar, agroecologia e mercado no Norte e Nordeste do Brasil. Fortaleza (CE): Fundação Konrad Adenauer; 2004.

[12] Campanhola C, Valarini P. A agricultura orgânica e seu potencial para o pequeno agricultor. Cadernos de Ciência \& Tecnologia. 2001;18(3):69-101.

[13] Instituto Nacional de Colonização e Reforma Agrária [Brasil]. Relatório de Gestão do Exercício de 2010. Brasília (DF): INCRA; 2005.

[14] Presidência da República. Balanço Geral da União 2010. Brasilia: CGU, 2011.

[15] Borges B. Projeto Mandala é apresentado a Marcos Palmeira e índio Xavante. Agência SEBRAE de Notícias.
2004 [acesso em 09 fev 2014]. Disponível em: http://www.agenciasebrae.com.br/noticia.kmf?noticia=2289 $\underline{615 \& \text { canal }=199}$

[16] SEBRAE. A agroecologia é uma atividade econômica em plena expansão - Entrevista com Aly N’Diaye. Revista SEBRAE AGRONEGÓCIOS. 2007;7:28-29.

[17] Oliveira MB. Ciência: Força Produtiva ou mercadoria? Crítica Marxista. 2005,21:77-96.

[18] Néder R. Direitos de propriedade comum das tecnologias sociais como ambiente de inovação social Termo de referência para um marco regulatório. Observatório do Movimento pela Tecnologia Social na América Latina. Brasília (DF): Centro de Desenvolvimento Social; 2009.

[19] Thomas H, Fressoli M, Lalouf A. Introdución. In: Thomas H, Buch A. (Org.). Actos, actores y artefactos. Herramientas para el análisis de los procesos de cambio tecnológico y cambio social. Bernal: Universidad Nacional de Quilmes Editorial; 2008. 